\title{
A Consumer Choice Theory Incorporating Behavioral and Spiritual Wisdom*
}

\author{
Tom Adi \\ Readware Institute, Gainesville, USA \\ Gaylene Nevers \\ Evan Business Consulting, Honolulu, USA
}

\begin{abstract}
A consumer makes choices by following a certain paradigm, a system for organizing his thinking based on norms that are determined by certain norm-setters or role models. Widespread societal ills such as depression and suicide seem to correlate with certain types of consumer behavior. However, current consumer choice theories don't appear to be effective in evaluating epidemiology research. This study compares existing consumer choice paradigms and introduces the linguistic paradigm as a framework for studying the organization of human thinking. The linguistic paradigm is based on the nature of human language and on spiritual wisdom. The paradigm is implemented to generate models (process templates) for the analysis of selected consumer choice issues. The potential effectiveness of these models in analyzing consumer behavior is discussed.
\end{abstract}

Keywords: consumer choices, norms, norm-setters, role models, semantics, systems of thinking

\section{Introduction}

Why are there tabloids and gossip media? Why does it seem that people are obsessed with the rich and famous? Does the desire to be something that is so out of reach correlate to depression, suicide and other individual and societal ills? Are people misinformed to believe that if they buy expensive items that they will fit in socially? Can a new set of information that readjusts consumer thinking lead to a paradigm that steers clear of the rich and famous and towards more realistic means?

The combination of depression and suicide is a current mental health problem that has been followed through government agencies. On another note, increasing circulation of celebrity news magazines and increasing celebrity advertising revenues can be indicators that the current culture of consumers is motivated to buy products containing the life styles of the rich and famous.

\footnotetext{
* Acknowledgments: Author Tom Adi wishes to thank his parents, family and friends, and especially his wife Brenda for their constant help and support. Brenda, a retired special education teacher, contributed to simplifying the presentation of the paradigm. Ken Ewell is especially acknowledged for his tireless efforts in discussing and promoting the theory since 1986 and also for co-creating its software implementation, Readware, as cofounder and CEO of Management Information Technologies, Inc. Tim Vogel invested much effort and funds in promoting Readware since 2008. Ken Ewell, his late wife Patricia Adi, Tim Vogel, Kim Payton and Jeannine Hippchen co-authored important papers about the theory. Finally, Lusana Hernandez contributed significantly to clarifying the presentation of the basic concepts of the theory.

Tom Adi, Ph.D., Director of Research, Readware Institute, Gainesville, Florida, USA.

Gaylene Nevers, M.Sc., economist, Evan Business Consulting, Honolulu, USA.

Correspondence concerning the economics aspects of this article may be addressed to Tom Adi, 2424 NW 47th Ln, Gainesville, FL 32605, USA. E-mail: tomadi59@gmail.com.
} 
People is a weekly American magazine of celebrity and human-interest stories, published by Time Inc.. With a readership of 46.6 million adults, People has the largest audience of any American magazine (Johnston-Greene, 2009).

The demand for TV advertising has been growing over the years and is forecast to grow further in the coming years. According to industry estimates, the global TV advertising market generated total revenues of $\$ 162 \ldots$ billion in 2012 and estimated for the 2012 to 2017 periods to reach $\$ 209$ billion by 2017. Moreover, the US is expected to continue its dominance of the global TV advertising revenues and is expected to continue to account for about $40 \%$ of the advertising revenues in 2017 (Time Warner Cable Inc, 2013).

According to a source from the Centers for Disease Control (CDC) in 2009, a third of the deaths from suicide tested positive for various overdoses including antidepressants (Karch, Logan, McDaniel, Parks, \& Patel, 2012).

Current consumer choice theories don't appear to be effective in evaluating epidemiology research. This study is an attempt to demonstrate a different paradigm of economic choices that may include a missing variable (spiritual wisdom). This paradigm identifies an individual's harmonic equilibrium of utility and happiness rather than a volatile disharmonic equilibrium or a total breakdown resulting in depression or suicide. This paradigm may offer behavioral economists a new maxim to assess and evaluate research for econometrics.

While econometrics does not offer a correlation between mental health disparities and the choice of norms and norm-setters, the linguistic paradigm does. It integrates the nature of human language with the economic, biological, social, psychological, and spiritual dimensions of human thinking, human development, and human growth. It also offers a value system and a universal modeling mechanism.

\section{Comparing Systems for Organizing Human Thinking}

Three systems for organizing human thinking are currently prominent (Figures 1, 2, and 3).
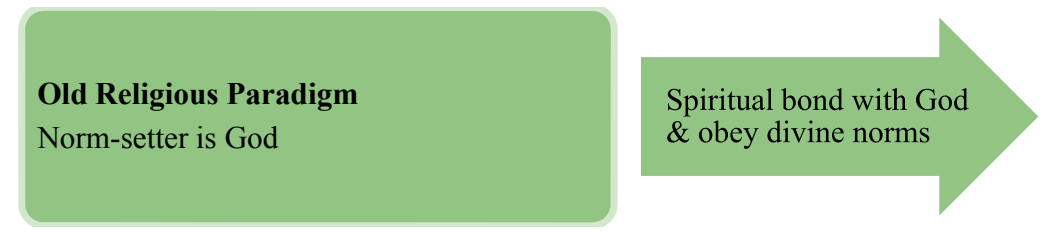

Happiness

Figure 1. Old religious paradigm.
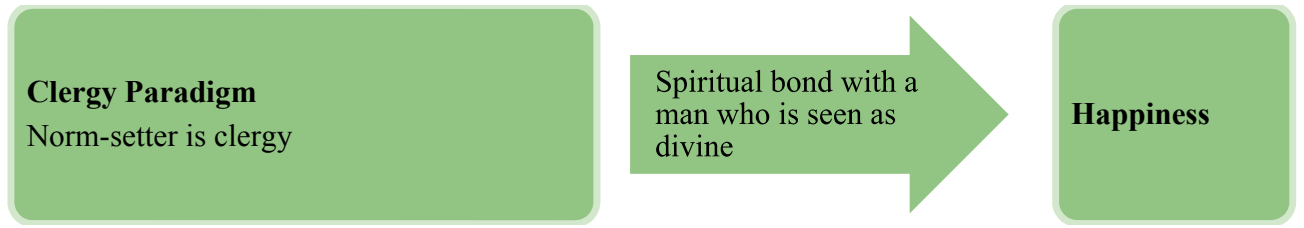

Figure 2. Clergy paradigm.

Modern Role-Model Paradigm

Norm-setter is a human role model;

Psychodynamic theory of personality;

Identity economics;

Celebrity worship;
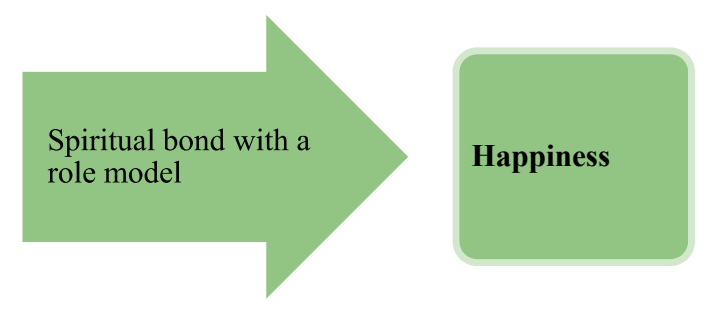

Figure 3. Modern role-model paradigm. 
In the old religious paradigm (Figure 1), God is regarded as the only norm-setter. The path to happiness requires establishing a total spiritual bond with God where man (the consumer), not informed enough to assess the utility of his actions, delegates all his decision-making to God, and obeys the divine norms in all his consumer choices, in order to achieve happiness in this world and the hereafter. This was the paradigm at the time of Moses and the Ten Commandments.

The clergy of different religions (Figure 2) offers a different paradigm. In order to achieve happiness, a consumer is not necessarily required to make choices according to divine norms. Rather, the consumer must surrender his soul to a special man with divine status in order to achieve happiness in both worlds. The clergy derives power from this paradigm: They, too, acquire some divine status and become the real norm-setters.

In the modern age (Figure 3), psychologists and behavioral economists offer consumer choice paradigms that are somewhat similar to the clergy paradigm. Instead of the special man with divine status, these paradigms have one or more role models whose status in the minds of consumers ranges from "psychologically influential" to "spiritual" or even "divine" in the broadest sense of these terms.

These human role models set the norms for different groups of people through their behavior. The consumer doesn't have to explicitly surrender his soul to the role models, but he would experience anxiety if he or others didn't act in conformity with the behavior of the role models. In other words, happiness lies in: (a) having some kind of spiritual bond with role models, and (b) emulating or imitating the role models.

One main focus of this study, celebrity worship, is closely related to this paradigm.

Following this type of paradigm, economists Akerlof and Kranton $(2000,2010)$ introduced the concepts "identity utility and identity economics" based on the psychodynamic theory of personality. "One's identity, or ego, or self" is based on the learning and internalization of a set of norms which a role model practices and with whom one identifies oneself. Conforming to role model norms causes a gain in utility and deviating from them leads to anxiety and loss of utility.

Kranton herself makes the following observations about the identity economics paradigm in the research of Huettel and Kranton (2012):

(1) In the short run, an individual chooses actions to maximize utility, assuming that social group belongings are known, his own characteristics are fixed, the norms of each group are fixed, and the actions of others are known;

(2) In the long run, however, he may modify all these assumptions by making his own choices to some extent. Social groupings (categories) may be more or less ascriptive, and in a society with fluid social boundaries, people may have some choice as to who they want to be;

(3) An individual's actions may also affect the norms of a social group, modify the definitions of the set of social groupings, as well as modify the status of each group;

(4) The identity utility function does not explain why people have strong group affiliations, why these affiliations are salient at some moments and not others, and the different behavior of individuals and subgroups (e.g. why younger people have stronger group affiliations and are more subject to group influence than older people);

(5) The utility function posits a trade-off between pecuniary rewards and non-pecuniary rewards, but it does not provide the foundations of that trade-off.

Huettel and Kranton (2012) suggested: 
Consulting the neurobiology of decision-making... to elaborate the effects of identity preferences on behaviour. For a better understanding of social preferences and social conflict, we must build a theory that incorporates the elements of identity (i.e. category concepts, norms and ideals) and describes the processes by which those elements guide decisions... recent work in neuroscience... has begun to link social cognition and decision-making.

Instead of looking for answers to such questions in neurobiology, this study presents a different consumer choice paradigm that may offer answers to many of these questions (Figure 4). The linguistic paradigm is based on the nature of human language, and more specifically, it is based on the nature of the original language of divine norms.

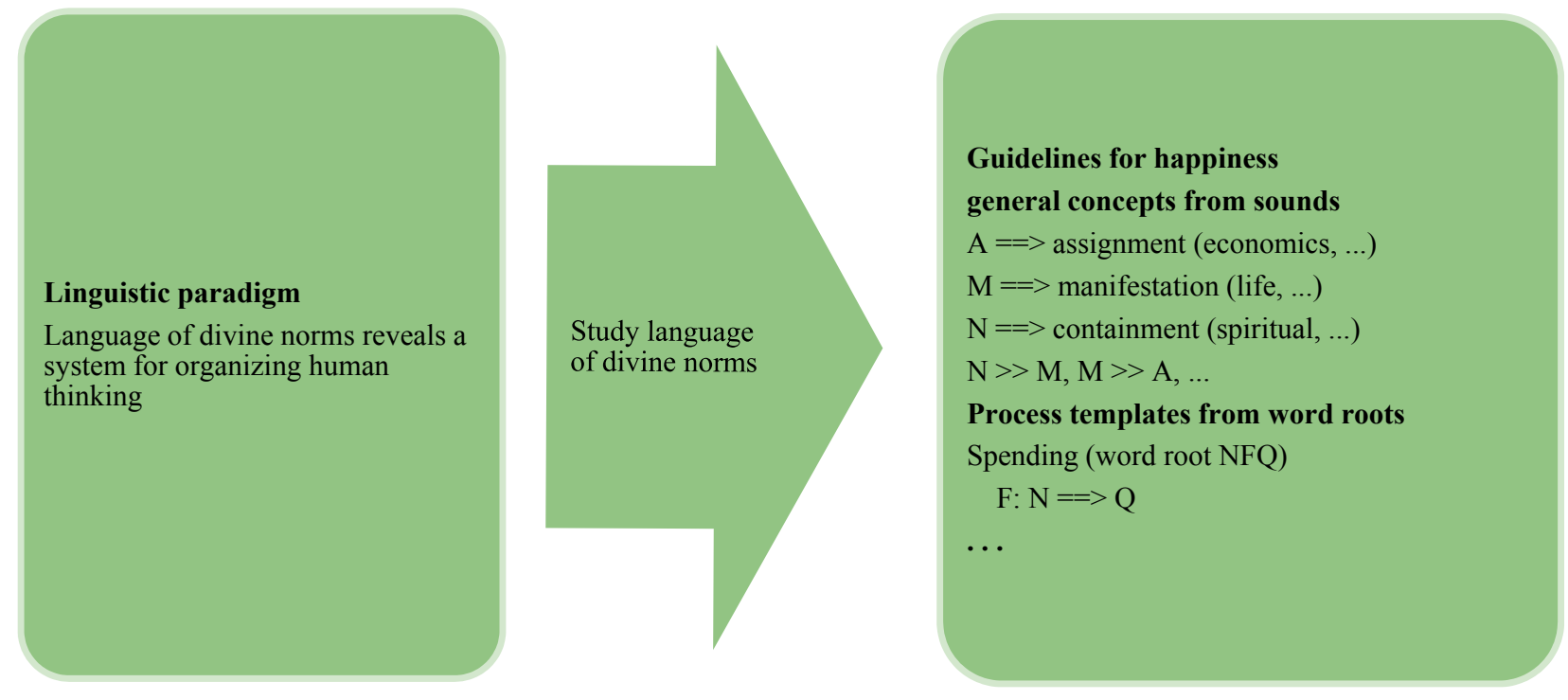

Figure 4. The linguistic paradigm: A better system for organizing human thinking.

The linguistic paradigm resembles the old religious paradigm in two ways: (a) God is the only norm-setter, and (b) a total surrender of one's soul to God is required. However, the language of the divine norms creates a dynamic relationship with God through general concepts, principles, and templates that are revealed in sounds, words, and passages. Instead of rigid, literal obedience to divine norms, the language of the divine norms inspires flexible guidelines in the form of concepts, principles, and templates for the adaptive empirical assessment of situations and for highly informed consumer decision-making procedures that can be adapted to changing circumstances.

\section{History of the Linguistic Paradigm and Its Implementation}

The history of the linguistic paradigm, its implementation in a top-performing search engine, its use to create a theory of cognition and a theory of emotions for artificial intelligence applications, and its use as a universal modeling system will be briefly reviewed below.

Until recently, linguists believed that the sounds of natural languages had no meanings at all (Saussure, 1916). Adi developed the first scientific theory of sound semantics (Adi \& Ewell, 1987; Adi, 1989, 2007) by generalizing from semantic observations (i.e., by induction) on the use of words in the Quran which is recognized as the reference for the perfect use of the Arabic language. However, he validated the same theory for the sounds of 20 different languages from East and West, including English, German, French, Russian, Greek, and Hebrew. The theory of semantics generates models of real-world processes from the sound concepts 
of word roots. This theory of semantics and its models is embedded in the Adi Theory of Cognition that contains system preservation norms for any type of system (T. Adi, Ewell, P. Adi, \& Vogel, 2009). When it comes to the semantic-cognitive models of human behavior, the objective of these norms is to preserve human functioning.

The semantic-cognitive models and norms which will be applied to consumer behavior in this paper have already been strongly validated in a large scale implementation. Four thousand of such models of all things were assigned to the English, German, and French dictionaries and implemented within the cognitive framework of system preservation norms into an intelligent search engine called Readware. Readware scored best performance in text retrieval at a global performance evaluation conference that was sponsored by The National Institute of Standards and Technology (TREC Conference, 2000; Voorhees \& Harman, 2000; T. Adi, Ewell, \& P. Adi, 1999, 2000). Sixty world-renowned colleges and corporations participated.

The main text retrieval task (manual ad hoc) was to find the 100 most relevant documents for each of 50 long queries in a pool of 500,000 documents. Readware performed much better than the Illinois Institute of Technology, Carnegie Mellon University, General Electric, IBM, Oracle and all the others. Moreover, Readware found around 500 relevant documents that nobody else was able to find.

Later, a theory of emotions was developed using the same modeling technique and its underlying preservation norms. The theory was published by invitation as chapter in a handbook of research on synthetic emotions and sociable robotics (Adi, 2009). Recently, models of many different human functions and real world processes were created in an invited update of this chapter in a special edition of a robotics journal and also in the Encyclopedia of Information Science and Technology (Adi, Ewell, Vogel, Payton, \& Hippchen, 2013, 2014).

The linguistic paradigm emerged out of a linguistic study of the semantics of divine norm texts such as the original Aramaic and Hebrew texts of the Bible and the Arabic text of the Quran. However, this delicate system of organizing human thinking is not preserved when the original divine norm texts have been re-interpreted, translated, or modified to fit certain viewpoints. Therefore, the only word and passage meanings that were relied upon in deriving the linguistic paradigm were those that are directly suggested by the grammar and the language of the original Arabic text of the Quran which has been preserved without any change. Word meanings from Arabic dictionaries and Quran commentaries had to be avoided in order to preserve consistency.

\section{Methodology}

The decision-making process of the consumer under the linguistic paradigm is based on analyzing each situation using process templates as assessment tools and decision-making procedures (Figure 5).

Process templates for assessing problem situations and making decisions emerge out of the combination of (a) concepts indicated by language sounds as suggested by the use of sounds in norm language and grammar, (b) structure of the sounds in the word roots of the vocabulary that describes a situation, (c) the way the vocabulary is used in the norm text, and (d) personal divine inspiration and intuitions about the interpretation of these concepts. This method for constructing a process template from an Arabic word root was formalized in previous publications (e.g., Adi et al., 2013, 2014) and also in the followings. 


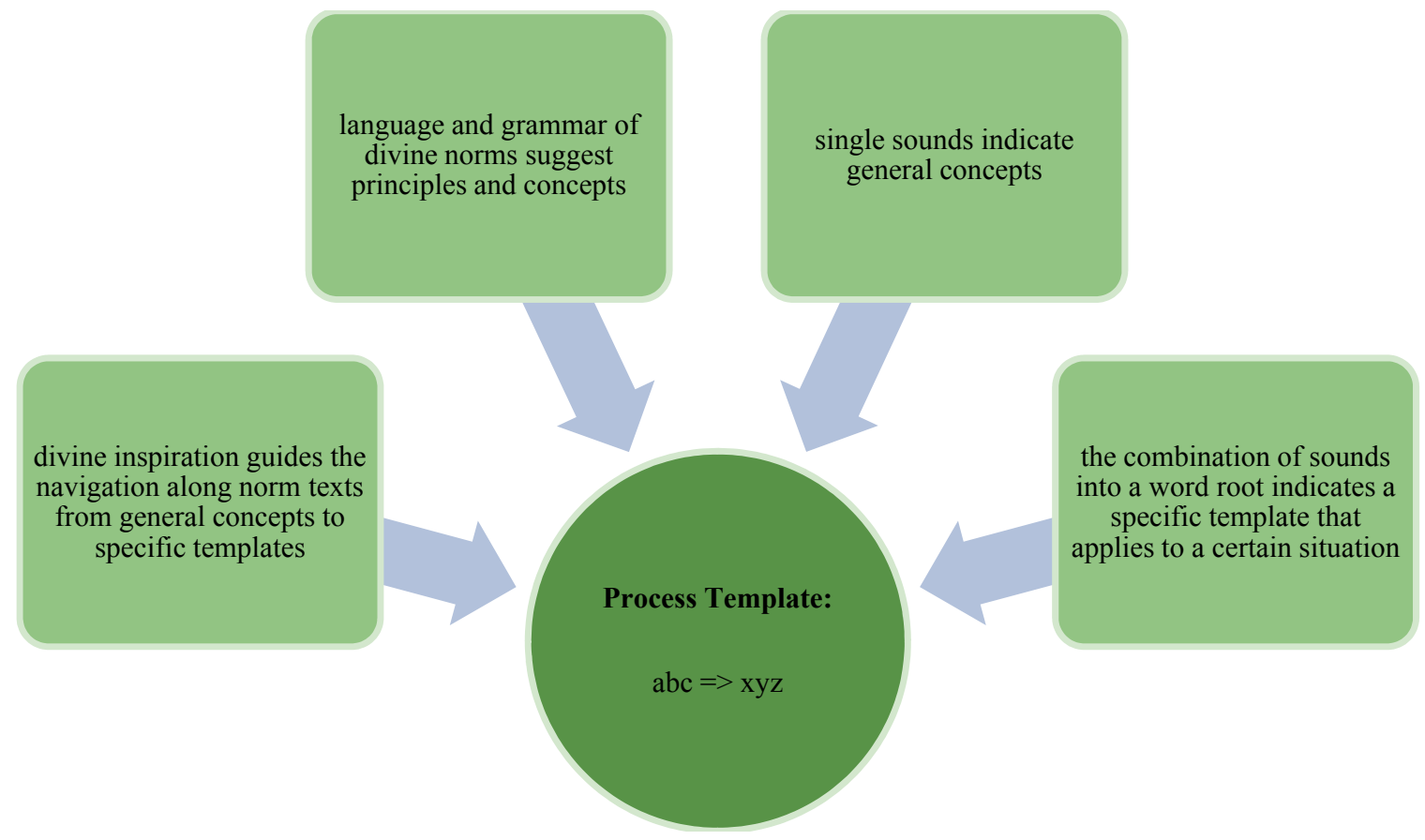

Figure 5. Generation of process templates for assessment and decision-making.

\section{Method of Constructing a Process Template: A Universal Modeling System}

A study of the meanings of the 28 Arabic sounds (consonants) as indicated by the language and grammar of the Quran resulted in Table 1 below (Adi, 1989, 2007). Arabic sounds that have no direct equivalents in English have been represented by underlined English characters (e.g. Q) for the sake of process template simplicity. The Arabic names of sounds (e.g. qaf) are in italics.

Table 1 basically says that each Arabic sound symbolizes a general process concept and a general process interaction concept. There are three general process concepts: assignment, manifestation, and containment which are used individually and also in combination with each other (compound concepts). There are four general process interaction concepts: closed-self, open-self, closed-others, and open-others. The meanings of these abstract concepts will be discussed below.

The rows of Table 1 are arranged in descending order of process nimbleness. Table 2 and 3 list the rules which determine inter-process control based on nimbleness. Using Table 1, 2 and 3, the sound structure of any Arabic word root can be mechanically converted into a general algorithmic model (GAM) that represents the flow of general types of interactions among general types of processes.

By replacing every general concept in a GAM with a specific concept (Table 4, 5, and 6), a specific algorithmic model can be obtained which is called a process template. Each general process/interaction concept (each GAM concept) represents an infinite number of specific concepts, i.e., every GAM represents countless process templates. The universal modeling system (UMS) is the fact that each GAM can be translated into a few process templates by using the specific concepts that are pinpointed by the Quran passages (also called muhkam passages) which contain this word root (Al-Qur'an, 1992). Such passages, which are generally accepted as the ultimate reference for the proper use of Arabic, also explain each word root (= GAM) they contain by pointing to specific interactions among specific processes. They do so through grammar and choice of words. With some divine inspiration, such explanations make it possible to construct process templates. 
Table 1

Concepts of Arabic Sounds (Names of Sounds Are in Italics), Rows in Descending Order of Process Nimbleness

\begin{tabular}{|c|c|c|c|c|}
\hline \begin{tabular}{|ll} 
Process type & Process interaction type \\
\end{tabular} & closed-self & open-self & closed-others & open-others \\
\hline assignment & 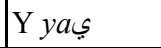 & A hamza أ & W waw g & H ha。 \\
\hline manifestation + assignment & R ra J & L lam & B $b a$ & T ta \\
\hline containment + assignment & S seen س & Zzay j & ص ص & $\underline{F}$ tha $ث$ \\
\hline containment + manifestation + assignment & $\underline{\mathrm{H}} h h a \mathrm{z}$ & S sheen ش & G geem ج & Zzza \\
\hline manifestation & M meem ? & ت & $\mathrm{D}$ dal & V thal ذ \\
\hline containment + manifestation & K kaf S & ض ض & T ttab & $\underline{\mathrm{X}} k h a \dot{\tau}$ \\
\hline containment & $\underline{\mathrm{O}}$ 'ain $\varepsilon$ & N noon ن & Q ق qaf & $\underline{\mathrm{G}}$ ghain $\dot{\varepsilon}$ \\
\hline
\end{tabular}

Table 2

\section{Standard Templates for Converting Three-sound Word Roots Into General Algorithmic Models (GAMs)}

Notes: Processes (sounds) with function symbol $\mathrm{f}$ control other processes. Their position in the word root determines escalation stage: $\mathrm{fXY}=$ initial (anticipate, begin, advance), $\mathrm{XfY}=$ intermediate (evolving, pending), $\mathrm{XYf}=$ final (realize, verify, actualize, test, rush, predict). Interaction type of process $f$ is part of the template.

\begin{tabular}{|c|c|}
\hline GAM Template (and conditions under which it applies) & GAM Formula \\
\hline $\begin{array}{l}\text { 1. Process } f \text { applies process } X \text { in open-self manner for process } Y \text {. } \\
\text { Process } f \text { has open-self interaction type and is more nimble than processes } X \text { and } Y \text {. Template applies } \\
\text { even if } X \text { and } Y \text { share process type. Root forms: } \mathrm{XY}, \mathrm{XfY}, \mathrm{XYf}, \mathrm{XfX} \text {. }\end{array}$ & $f: X==Y$ \\
\hline $\begin{array}{l}\text { 2. Process f returns process } \mathrm{Y} \text { in closed-self manner to process } \mathrm{X} \text {. } \\
\text { Process } \mathrm{f} \text { has closed-self interaction type and is more nimble than processes } \mathrm{X} \text { and } \mathrm{Y} \text {. Even if } \mathrm{X} \text { and } \mathrm{Y} \\
\text { share process type. Root forms: } \mathrm{XX}, \mathrm{XfY}, \mathrm{XYf}, \mathrm{XfX} \text {. }\end{array}$ & $\mathrm{f}: \mathrm{X}<==\mathrm{Y}$ \\
\hline $\begin{array}{l}\text { 3. Process f joins process } \mathrm{X} \text { with process } \mathrm{Y} \text { in closed-others manner. } \\
\text { Process } \mathrm{f} \text { has closed-others interaction type and is more nimble than processes } \mathrm{X} \text { and } \mathrm{Y} \text {. Even if } \mathrm{X} \text { and } \mathrm{Y} \\
\text { share process type. Root forms: } \mathrm{XXY}, \mathrm{XfY}, \mathrm{XYf}, \mathrm{XfX} \text {. }\end{array}$ & $\mathrm{f}: \mathrm{X}<==>\mathrm{Y}$ \\
\hline $\begin{array}{l}\text { 4. Process } \mathrm{f} \text { disengages process } \mathrm{X} \text { from process } \mathrm{Y} \text { in open-others manner. } \\
\text { Process } \mathrm{f} \text { has open-others interaction type, is more nimble than processes } \mathrm{X} \text { and } \mathrm{Y} \text {. Even if } \mathrm{X} \text { and } \mathrm{Y} \text { share } \\
\text { process type. Root forms: } \mathrm{XYY}, \mathrm{XfY}, \mathrm{XYf}, \mathrm{XfX} \text {. }\end{array}$ & $\mathrm{f}: \mathrm{X}>==<\mathrm{Y}$ \\
\hline
\end{tabular}

Table 3

Non-standard Templates for Converting Three-sound Word Roots Into General Algorithmic Models (GAMs)

GAM Template (and conditions under which it applies)

( $\mathrm{Y}, \mathrm{A}$, or $\mathrm{W}$ : The sound $\mathrm{Y}, \mathrm{A}$, or $\mathrm{W}$ is dropped in some word forms and can therefore be ignored.)

5. Process $f$ is applied to duplicate process $x$. Process $f$ is more nimble than duplicate process $x$. Root forms: fxx, xxf.

6. Process $\mathrm{f}$ is applied to process $\mathrm{x}$. First or third sound in word root $\mathrm{u}$ is $\mathrm{Y}, \mathrm{A}$, or $\mathrm{W}$, and process $\mathrm{f}$ is more nimble than process $x$. Root forms: ufx, uxf, fxu, xfu.

7. Process $\mathrm{x}$ is first subjected to process $\mathrm{g}$ and then subjected to process $\mathrm{f}$. Word root form is fgx or $\mathrm{xgf}$, and processes $\mathrm{f}$ and $\mathrm{g}$ share process type and are more nimble than process $\mathrm{x}$. Special cases: ffx, $\mathrm{xff}$.

8. Process $\mathrm{x}$ is subjected to processes $\mathrm{f}$ and $\mathrm{g}$ simultaneously or in alternating manner.

Word root form is fxg, and processes $\mathrm{f}$ and $\mathrm{g}$ share process type and are more nimble than process $\mathrm{x}$.

Special case: fxf.

9. The two processes $f$ and $g$ are applied simultaneously to something. Root form is fug and $u$ is $Y$, A, or

W. Special case: fuf.

10. Something is first subjected to process $g$ and then subjected to process $f$. Root form is ufg or fgu and $u$ is $¥, A$, or $廿$, and processes $f$ and $g$ share process type.

11. Something is first subjected to process $h$, then subjected to process $g$, and then subjected to process $f$. All processes $\mathrm{f}, \mathrm{g}$, and $\mathrm{h}$ share process type. Root form: fgh.

12. Process $\mathrm{f}$ is applied to something. Root has two occurrences of $¥, \mathrm{~A}$, or $\mathrm{W}$.

GAM Formula

$f\left(x^{2}\right)$

$f(x)$

$\mathrm{f}(\mathrm{g}(\mathrm{x}))$

$f(x) \& g(x)$

$f() \& g()$

$\mathrm{f}(\mathrm{g}())$

$\mathrm{f}(\mathrm{g}(\mathrm{h}(\mathrm{)}))$

$\mathrm{f}()$ 
Table 4

\section{Examples of Specific Concepts Represented By General Process Interaction Concepts}

\begin{tabular}{|c|c|}
\hline closed-self & $\begin{array}{l}\text { all, anchoring, automatic, backward, baseline, blocking, calm, calming, a certain..., circle, come home, } \\
\text { complementary, complete, completing (satisfying needs), correct, cul-de-sac, dead-end, defined, enclosed, } \\
\text { enough, familiar, full, genuine, history, home, homing, idle, impede, inactive, independent, inhibitory, input, } \\
\text { involuntary, inward, motionless, natural, obstruct, old, one's own, oneself, out of a sense of duty, out of a sense } \\
\text { of responsibility, passive, past, perfect, perfecting, personal, positive, precise, preservation, private, } \\
\text { prohibiting, react, reactive, real, receive, reduce, refer, reflex, regress, relegate, repeat, response, resting, } \\
\text { restrain, restraining, restrict, return, same, satisfy, satisfying, saturate, self, self-contained, self-restrained, } \\
\text { shielded, shut down, similar, steady, still (not moving), sufficient, thwart, true, turn in, a type of, valid, } \\
\text { well-defined, whole, yes }\end{array}$ \\
\hline open-self & $\begin{array}{l}\text { act out, active, another (not self), anticipatory, arbitrary, artificial, away, deficient, detailed, directed toward } \\
\text { others, directed toward something, discretionary, empty, excitatory, excited, to face, false, following, for } \\
\text { others, forward, free, freely, future, incomplete, go out, invalid, lacking, loose, moving, need, negative, new, } \\
\text { no, not, offer, open to others, open-ended, others (not self), output, outward, promising, public, rejecting (no), } \\
\text { release, send, some, someone, stimulus, trigger, toward others, turn out, unavailable, uncertain, undefined, } \\
\text { unfamiliar, unfold, unknown, unleash, unnatural, unspecified, violation, voluntary (freely), vulnerable, weak }\end{array}$ \\
\hline closed-others & $\begin{array}{l}\text { add, balance, balanced, balancing, between, bind, build, challenge, clash, cohesive, collision, combine, coming } \\
\text { (pending), commit (engage), common, compare, confrontation, connect, constructive, continue, counteract, } \\
\text { deadlock, defend, a draw, dual, engage, engaged, equal, everything, extend, fold, general, good (constructive), } \\
\text { increase, increment, inside, integrate, internal, join, maintain, meet, moderate, multiple, mutual, pending, the } \\
\text { present, prevalent, reciprocal, reciprocate, repair, reward, shared, solid, stabilizing, stalemate, standoff, } \\
\text { supportive, together, ubiquitous, universal, widespread, within environment, x for y }\end{array}$ \\
\hline open-others & $\begin{array}{l}\text { absence, absent, aggressive, apart, attack, beyond environment, choose, contrast, corrupted, cut, decrease, } \\
\text { decrement, defensive, destructive, detach, disconnect, disengage, disintegrate, distinguish, eternal, exchange, } \\
\text { exceptional, excessive, exclude, exclusive, exquisite, external, extreme, imbalance, out of this world, outside, } \\
\text { punish, separate, special, specific, specify, split, stop, subtract, target, targeted, third-party, timeless, } \\
\text { unengaged, uncommon, unequal, unfold, unravel }\end{array}$ \\
\hline
\end{tabular}

\section{Table 5}

\section{Examples of Specific Concepts Represented By Individual General Process Concepts}

\begin{tabular}{|l|l|}
\hline $\begin{array}{l}\text { assignment } \\
\text { low intensity } \\
\text { most nimble }\end{array}$ & $\begin{array}{l}\text { associate, attach, attention, attentive, cause to become , confirm, connect, concentrate, consider, dedicate, } \\
\text { designate, determine, to direct, an element, exist, focus, happen, identify, identity, intense (concentrated), } \\
\text { intention, link, manage (direct), particle, point, point of view, to project, pulse, regard as, represent (symbol), } \\
\text { scan, select, sign, signal, symbol, tag, treat as, turn to, a unit, view as, wave }\end{array}$ \\
\hline $\begin{array}{l}\text { manifestation } \\
\text { medium } \\
\text { intensity } \\
\text { less nimble }\end{array}$ & $\begin{array}{l}\text { action, active, activity, agency, agent, appearance, apply, attitude, attribute, body, case, channel, circumstance, } \\
\text { concept, condition, context, dimension, display, emotion, entity, essence, event, example, execute, to } \\
\text { experience, express, feel, fill (manifest), form, fulfill, implement (realize), instance, instantiation, idea, } \\
\text { instrument, interpret, location, manner, mass, matter, medium, method, motion, number (manifested), object, } \\
\text { person, phenomenon, physical, place, process, reality, realization, represent (manifest), shape, show, situation, } \\
\text { space, state, status, substance, time, translate, value, vessel }\end{array}$ \\
\hline $\begin{array}{l}\text { containment } \\
\text { high intensity } \\
\text { least nimble }\end{array}$ & $\begin{array}{l}\text { ability, awareness, capacity, collect, collector, command, conscious, consciousness, contain, container, content, } \\
\text { control, data, energy, force, holy, information, an instruction, law, model (order), norm, number (quantity), } \\
\text { order, power, quantity, rule, sound, speech (sounds), spirit, strength, volume, weight, word (sounds) }\end{array}$ \\
\hline
\end{tabular}

Table 6

\section{Examples of Specific Concepts Represented By Compound General Process Concepts}

\begin{tabular}{|l|l|}
\hline $\begin{array}{l}\text { manifestation }+ \\
\text { assignment }\end{array}$ & $\begin{array}{l}\text { acquire, administer (decide), allocate (assign place), attention on manifestation, attention on person, attentive } \\
\text { activity, belong (assign place), bond, commitment, concentrated activity, consideration of value, decide (assign } \\
\text { action), decision, decision maker, directed action, erupt (assign event), focus of activity, focused activity, hit } \\
\text { (action connects), image (projected manifestation), implement (determine realization), intense activity, interact } \\
\text { (connect by action), interest, interpretive link, manage (decide), to own, placement (assign place), position, } \\
\text { project form, project manifestation, relationship (connect by activity), relative to manifestation, scan } \\
\text { instantiations, select concept, set (elements in a place), set up (assign manifestation), supply (assign substance) }\end{array}$ \\
\hline $\begin{array}{l}\text { containment }+ \\
\text { assignment }\end{array}$ & $\begin{array}{l}\text { assess (assign quantity), attack (directed force), burden (assigned weight), confirmed data, design, fill (assign } \\
\text { content), line (ordered points), lodge (assign container), measure (assess), model (ordered symbols), posture } \\
\text { (structure), push (focus force), sensing (measure), sensory, sequence (assign order), statement (connected } \\
\text { words), stream (sequence), structure (assign order), supervise (assign order), supervisor, text (connected words) }\end{array}$ \\
\hline
\end{tabular}


Table 6 to be continued

\begin{tabular}{|l|l|}
\hline $\begin{array}{l}\text { containment }+ \\
\text { manifestation }\end{array}$ & $\begin{array}{l}\text { lant of an order, algorithm (execute instructions), apply law, apply force, apply model, coerce, control } \\
\text { (manifestation of order/power), controller, display of force, effort (apply energy), field (force in space), fill } \\
\text { container, form of energy, interpretation of law, mapping (realizes rules), mood, powerful agent, pressure } \\
\text { (apply force), propel (force causes action or motion), sovereign area (space of power), theory (interpretation of } \\
\text { law), violent activity (activity with force), worth (value quantity) }\end{array}$ \\
\hline $\begin{array}{l}\text { containment }+ \\
\text { manifestation }+ \\
\text { assignment }\end{array}$ & $\begin{array}{l}\text { lgorithm (directed execution of instructions), analyze, behavior (process), conspiracy (system), experience, } \\
\text { inborn (systemic, from life), innate (systemic, from life), life, living being (system), mechanism (process), } \\
\text { motion, object (static view of process), organism, plan, process (assignment and manifestation of control), } \\
\text { system (process), systematic, systemic, thing (object) }\end{array}$ \\
\hline
\end{tabular}

Process templates are adaptive. They evolve through implementation experience and by revisiting UMS, which thus acts as a tool for learning, research and discovery

\section{Detailed Example of Creating a Process Template}

The following is a detailed example of how a process template is created.

Taking the Arabic word root AMN (أمن) as an example, its English meanings are "trust and faith" and its root form (see Table 2) is "fXY". Then, its GAM formula can be obtained from Table 2:

$$
f: X \rightarrow Y
$$

GAM formula using Arabic sounds (Table 1):

\section{$A: M \rightarrow N$}

The escalation stage (see Table 2) is initial (anticipate), because the function sound A is first in root.

The GAM template can be obtained from Table 2: Template 1-process $\mathrm{f}$ applies process $\mathrm{X}$ in open-self manner for process Y; GAM (translation of GAM template using Table 1 and Table 2): trust - anticipatory (escalation stage) assignment $\mathrm{A}$ applies closed-self manifestation $\mathrm{M}$ in open-self manner for open-self containment $\mathrm{N}$.

The raw process template (GAM concepts replaced by specific concepts from Table 4 and Table 5 as pinpointed by the muhkam expression "they have faith in what they cannot see") is: trust-anticipatory (escalation stage) point of view (=assignment, Row 1 of Table 5) A applies positive (= closed-self, Row 1 of Table 4) attitude (= manifestation, Row 2 of Table 5) $\mathrm{M}$ in future (= open-self, Row 2 of Table 4) manner for unavailable (= open-self, Row 2 of Table 4) data (= containment, Row 3 of Table 5) N; refined process template: trust-anticipatory point of view to have a positive attitude toward the future when data is unavailable.

\section{Adapting the Linguistic Paradigm to Behavior and Economics}

The language of divine norms forms the basis of a daily behavioral-spiritual quest for wisdom. When the consumer encounters a problem, he thinks about the words and word roots that he would use in his empirical study of this problem. Some of the key terms that he uses to describe the problem are likely to be found as word roots in divine norm texts.

As indicated by comments from Huettel and Kranton (2012) in the previous section, a consumer who follows a paradigm that is determined by a human role model must make his choices and decisions based on vague and fluctuating personal opinions of others, as well as his own vague and fluctuating personal opinions. On the other hand, the consumer who follows the linguistic paradigm can make his choices and decisions based on empirical assessments using decision-making process templates that were derived from the language of divine norms. He uses these tools according to his own informed judgment. He is an intellectually more 
advanced consumer. What is helpful currently is that people have first-hand access to all sources of information through the internet. They have realized that the media is biased toward opinions of role models and they have learned to become more discerning.

It is not the authors' intent to suggest that every consumer should be able to elicit fresh process templates for his daily problems by studying divine norms. Rather, some economic process templates have been constructed by the authors from certain word roots and their usefulness for the purposes of this study will be discussed. Similarly, scientists and experts can construct different process templates from other word roots and they can explain their usage to others.

The following table of the concepts that are indicated by Arabic sounds (Table 7) is based on Table 1 above. Table 7 explains the basis of the dynamic structure of economic process templates. Table 1 was developed in 1985 for cognitive theory modeling (Adi, 1989, 2007). Table 7 adapts Table 1 to human development and economics in order to test the linguistic paradigm on consumer choices. The columns of Table 1 have been rearranged to reflect the stages of human development. The rows of Table 1 have been rearranged to reflect value system priorities which form the basis of economic trade-offs.

Table 7

Behavioral and Economic Concepts of Arabic Sounds (Consonants)

\begin{tabular}{|c|c|c|c|c|}
\hline $\begin{array}{l}\text { Interaction type: } \\
\text { Process type: } \\
\text { value system } \\
\text { behavioral trade-off value, } \\
\text { highest to lowest }\end{array}$ & $\begin{array}{l}\text { closed-self: } \\
\text { necessary, ... }\end{array}$ & $\begin{array}{l}\text { closed-others: } \\
\text { without } \\
\text { hardship, ... }\end{array}$ & $\begin{array}{l}\text { open-self: } \\
\text { excellent, ... }\end{array}$ & $\begin{array}{l}\text { open-others: } \\
\text { heavenly, ... }\end{array}$ \\
\hline containment: spiritual, behavioral, ... & $\underline{O}$ ain $\varepsilon$ & Q & N noon ن & $\underline{\mathrm{G}}$ ghain $\dot{\varepsilon}$ \\
\hline containment + manifestation: spiritual + life,$\ldots$ & K kaf S & T ttab & ض ض & $\underline{\mathrm{X}} k h a \dot{\tau}$ \\
\hline manifestation: life,$\ldots$ & M meem ? & D dal & F & V thal ذ \\
\hline $\begin{array}{l}\text { containment }+ \text { manifestation }+ \text { assignment: } \\
\text { spiritual }+ \text { life }+ \text { economic }, \ldots\end{array}$ & $\underline{\mathrm{H}} h h a \tau$ & G geem ج & ش & $\underline{Z} z z a$ b \\
\hline $\begin{array}{l}\text { containment }+ \text { assignment: } \\
\text { spiritual }+ \text { economic }, \ldots\end{array}$ & س S S seen & ص ص & Zzayj & $\underline{\mathrm{F}}$ tha $ث$ \\
\hline manifestation + assignment: life + economic,$\ldots$ & $\mathrm{R} r a \mathrm{~J}$ & B $b a+$ & Llam J & T $t a ت$ \\
\hline assignment: economic, ... & Yya & W waw g & A hamzal & H ha。 \\
\hline
\end{tabular}

As mentioned above, Arabic has 28 sounds (consonants) each of which has a unique cell in this $4 \times 7$ table of sound concepts. Arabic sounds that have no direct equivalents in English have been represented by underlined English characters for the sake of process template simplicity. Since its inception in 1985 and despite decades of research and development, not a single sound has changed its cell position in the table.

Although the same sound concepts are valid for all alphabetic languages, some of the 28 sounds are missing in most languages (see Table 8 for the concepts of English sounds).

Each cell of the table (each sound) represents:

- a general process concept (the row);

- a general process interaction concept (the column, also called orientation or polarity).

Each general sound concept (each cell) represents an infinite number of specific concepts that distinctly differ from those of any other sound concept. As explained in Figure 4 above, sound concepts are indicated by 
the original language of divine norms. This language determines which few specific concepts out of the infinite sets of concepts to choose for a certain situation. When linguists observed that each sound represented an endless number of specific concepts, they came to the false conclusion that the choice of sounds for words is arbitrary and that single sounds are not associated with any specific concepts at all (Saussure, 1916).

The 28 sounds indicate three general process concepts:

- containment;

- manifestation;

- assignment.

These abstract concepts generally represent three aspects of human functioning:

- the spiritual (including psychological);

- life (including the social);

- the economic.

The rows of the table contain all possible combinations of these three elementary concepts, without repetitions. When two concepts are combined, the compound concept not only contains their combination, but also offers a different emergent general concept that represents an infinite number of distinct specific concepts, for example, when containment and assignment are combined, one of the emergent concepts is "series". Similarly, when the spiritual and life aspects are combined, one of the emergent concepts is "human norm-setter". As it turns out: manifestation + assignment = set concept; life + economic = bond; and so on.

There is an order of importance in the rows. The concepts of the first row are more important than the concepts of the second row, and so on. The "socio-legal ontology" is also seen (Adi et al., 2009). This general order of priority is shared by all legal and spiritual systems (Al-Shatibi, 1996).

Table 8

Concepts of English Sounds

\begin{tabular}{|c|c|c|c|c|}
\hline $\begin{array}{l}\begin{array}{l}\text { Interaction type: } \\
\text { stages of human growth, } \\
\text { lowest to highest } \\
\text { value system } \\
\text { behavioral trade-off value, } \\
\text { highest to lowest }\end{array} \\
\end{array}$ & $\begin{array}{l}\text { closed-self: } \\
\text { necessary, ... }\end{array}$ & $\begin{array}{l}\text { closed-others: } \\
\text { without } \\
\text { hardship, ... }\end{array}$ & $\begin{array}{l}\text { open-self: } \\
\text { excellent, ... }\end{array}$ & $\begin{array}{l}\text { open-others: } \\
\text { heavenly, ... }\end{array}$ \\
\hline containment: spiritual, behavioral, ... & missing & Q CQ & N GN KN & NC NG NK \\
\hline containment + manifestation: spiritual + life,$\ldots$ & $\mathrm{K}$ & Missing & missing & $\mathrm{CH}$ GH X \\
\hline manifestation: life, ... & $\mathrm{M}$ & $\mathrm{D}$ & F P PH & $\mathrm{TH}$ \\
\hline $\begin{array}{l}\text { containment }+ \text { manifestation }+ \text { assignment: } \\
\text { spiritual }+ \text { life }+ \text { economic }, \ldots\end{array}$ & missing & G & $\mathrm{SH}$ & missing \\
\hline $\begin{array}{l}\text { containment }+ \text { assignment: } \\
\text { spiritual }+ \text { economic }, \ldots\end{array}$ & $\mathrm{S}$ & $\mathrm{C} \mathrm{CK}$ & Z & missing \\
\hline manifestation + assignment: life + economic,$\ldots$ & $\mathrm{R}$ & B & $\mathrm{L}$ & $\mathrm{T}$ \\
\hline assignment: economic,$\ldots$ & I- J Y- & O- U- V W & A- & E H \\
\hline
\end{tabular}

The following diagram (Figure 6) is another way of explaining the rows of the table.

The spiritual is expected to have influence over everything else. It should never be traded off for anything else. Human life and social bonds have priority over the economic aspects of life, but the spiritual realm has priority over life and social aspects. If trade-offs have to be made, then lower-priority things may be traded off for higher-priority things. 
The columns of the table represent the four aspects of process interaction:

- closed self;

- closed others (or closed group);

- open self;

- open others (or open group).

Although these abstract process interaction concepts represent an infinite number of specific process interaction concepts, they generally symbolize concepts that people encounter in the four stages of human development:

- what is necessary (for survival);

- what eliminates or reduces hardship (for comfort);

- what is excellent (for beauty);

- what is heavenly or wonderful (beyond this life).

Moreover, even as the different stages of human development have an order of priority, they may not be traded off for each other, for example, the first column is less-developed than the second column, but survival should not be traded off for the sake of reducing hardship.

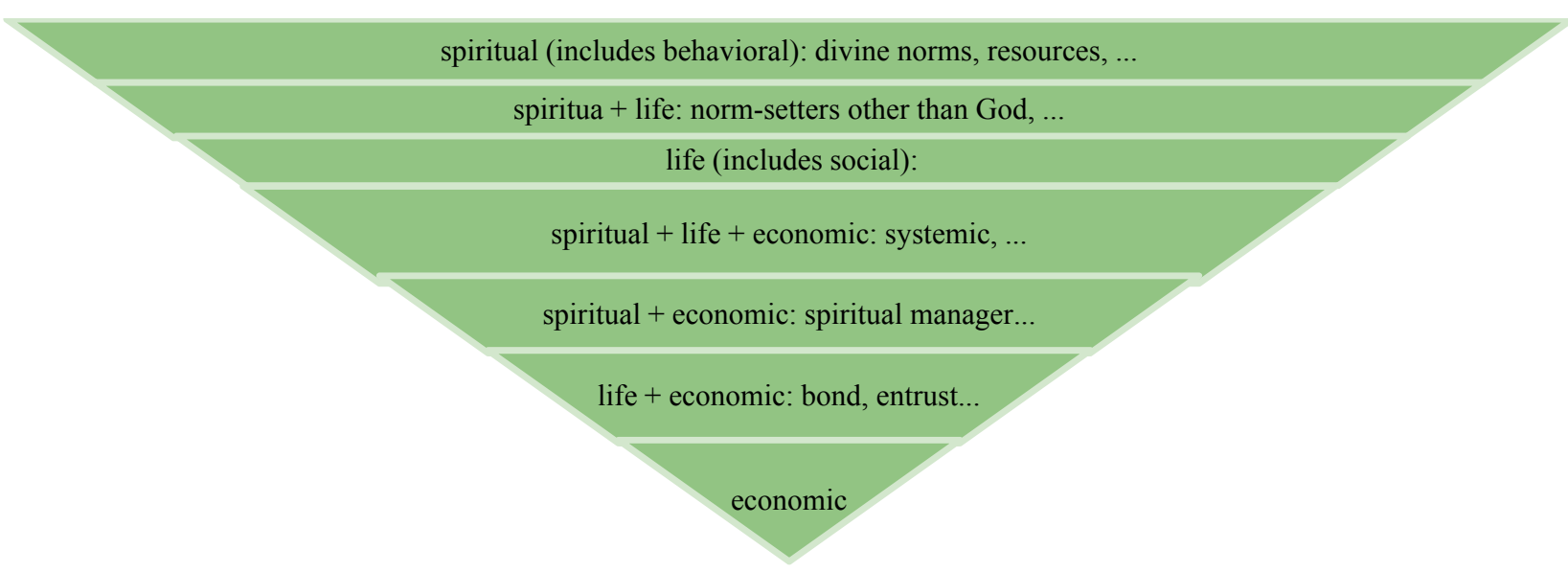

Figure 6. Value system for the different aspects of human functioning.

\section{Results of Applying the Linguistic Paradigm to Consumer Choices}

During weeks of critical analysis, economic concepts were identified by Arabic word roots and eight process templates were created from them by the authors for the purpose of consumer choice issues. In this section, these templates will be discussed.

As mentioned earlier, the specific concepts encountered in these templates are not limited to concepts discussed in previous sections. Although the general concepts are distinct and well-defined, the possible number of the specific concepts which they represent is infinite. Still, the language and grammar of the original divine norms pinpoint the path from general theoretical concepts to specific practical concepts. The navigation from the general to the specific through the use of norm language and grammar is beyond the scope of this study. It has been documented in unpublished manuscripts and audiovisual lectures that can be requested from the authors.

Process templates were created for the following consumer issues: (1) utility, (2) happiness, (3) spending, (4) income, (5) harmonious equilibrium, (6) breakdown, (7) choice of norm-setter, and (8) the illusory norm-setter. 


\section{Process Templates for Utility and Happiness}

Table 9, Figure 7, and Figure 8 show process templates from the linguistic paradigm for the concepts of utility and happiness.

Table 9

Specific Concepts for the Sounds of the Word Roots for Utility and Happiness (in Italics in Row and Column Headings)

\begin{tabular}{|l|l|l|l|l|}
\hline & $\begin{array}{l}\text { closed-self: } \\
\text { complete, sound }\end{array}$ & closed-others & $\begin{array}{l}\text { open-self: } \\
\text { lack, flaw }\end{array}$ & open-others \\
\hline containment (spiritual): resources & $\underline{\mathrm{O}}$ & & $\mathrm{N}$ & \\
\hline containment + manifestation & & & & \\
\hline manifestation (life):resolve, transaction, state & $\mathrm{M}$ & & $\mathrm{F}$ & \\
\hline
\end{tabular}

$\mathrm{N}$ : Individual or social lack or flaws in specific resources
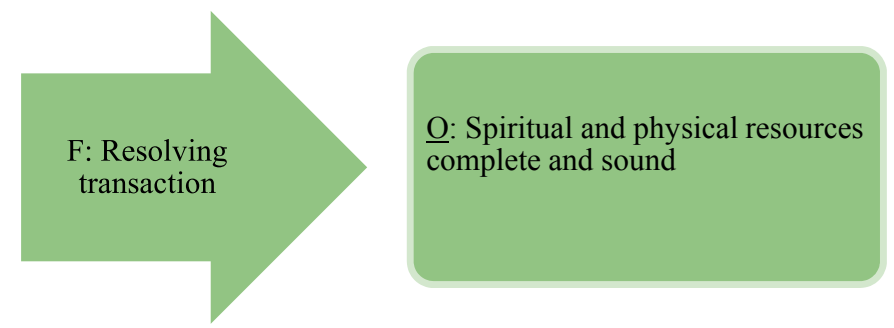

Figure 7. Utility (Arabic word root NFO): Transaction (F) that resolves lack or flaws in some resources (N) so that those resources become complete and sound $(\underline{\mathrm{O}})$. Imbalance to balance.
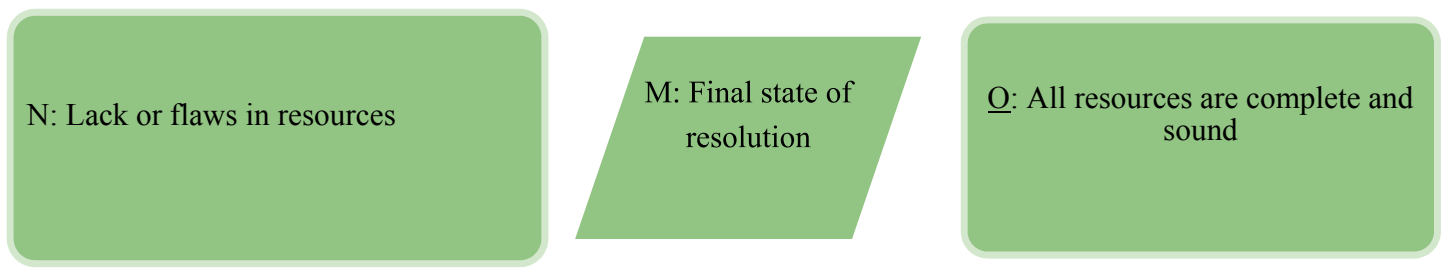

Figure 8. Happiness (NoM): Final state (M) in which all lack and flaws in resources $(\mathrm{N})$ have been resolved by received resources $(\underline{\mathrm{O}})$.

The utility function and the happiness emotion concepts are both represented in the linguistic paradigm. Table 7 is partly reproduced in Table 9. New specific concepts are highlighted in italics in the row and column headings. The Arabic sounds of the word roots for utility (NFO) and happiness (NOM) are found on two rows of the table (first and third rows): spiritual (resources) and life (manifestation/resolve). The ideas of both the utility concept (NFO) (Figure 7) and the happiness emotion (NOM) (Figure 8) move along the resolution axis ( $\mathrm{F}$ or $\mathrm{M}$ ) from the deficient ( $\mathrm{N}$ in third column: lacking some resources) towards identifying and acquiring necessary resources or adapting to available resources for survival (므: resources are complete and sound). Happiness is identified as the "final state" (M being the final sound in the word root NoM), supposing that utility is a flow, and that an accumulation of maximizing utility over time, or in the long run, is happiness, a stock.

There are two differences between conventional economic theory and the linguistic paradigm in this chart. The first difference is the inclusion of spiritual wisdom and the second one is that happiness is a stock. Figure 7 and 8 are representations of accumulated assessment and reassessment to meet all spiritual, life, and economic needs in the long run. 
The deduction of applying the linguistic sound concepts for the economic modeling has thus been proven and justified for the first set of consumer choice theory concepts.

\section{Process Templates for Income and Spending}

Table 10 and Figure 9, 10 show process templates from the linguistic paradigm for the concepts of income and spending. They demonstrate the need for spiritual insight. They support the notion that when money is spent, typically, the goal is to attain happiness in the long run. Spiritual insight embraces delayed gratification if necessary. The focus is on resolving flaws and lacks rather than responding to cravings and instant gratification behavior (animal spirits), or spending in conformity with group norms.

Table 10

Specific Concepts for the Sounds of the Word Roots for Income and Spending (in Italics in Row and Column Headings)

\begin{tabular}{|l|l|l|l|l|}
\hline & $\begin{array}{l}\text { closed-self: } \\
\text { limited }\end{array}$ & $\begin{array}{l}\text { closed-others: } \\
\text { common }\end{array}$ & $\begin{array}{l}\text { open-self: } \\
\text { private }\end{array}$ & open-others \\
\hline containment (spiritual): resources & & Q & N & \\
\hline containment + manifestation & & & & \\
\hline manifestation (life):transfer & $\mathrm{M}$ & & $\mathrm{F}$ & \\
\hline spiritual + life + economic & & & & \\
\hline spiritual + economic: shares & & & $\mathrm{Z}$ & \\
\hline life + economic: entrust & $\mathrm{R}$ & & & \\
\hline
\end{tabular}

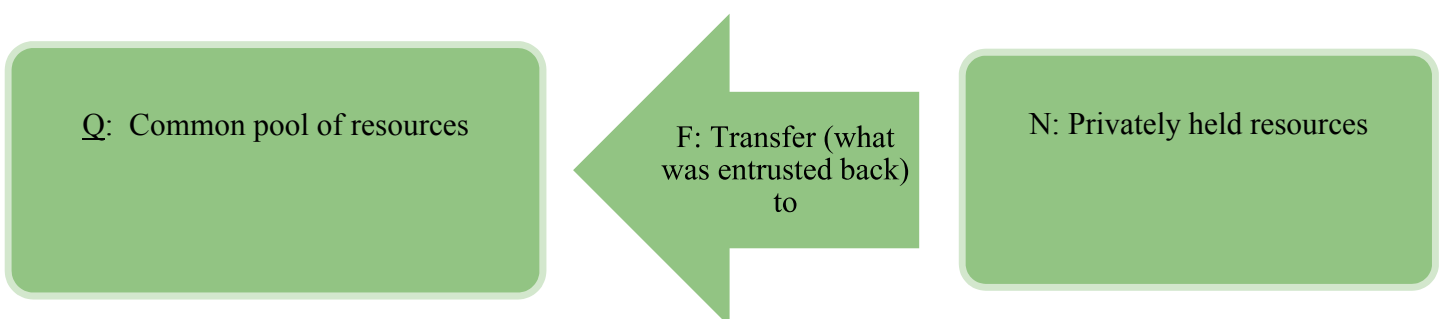

Figure 9. Spending (NFQ): Transfer (F) of some privately held resources $(\mathrm{N})$ back into the common pool of resources $(\underline{Q})$.
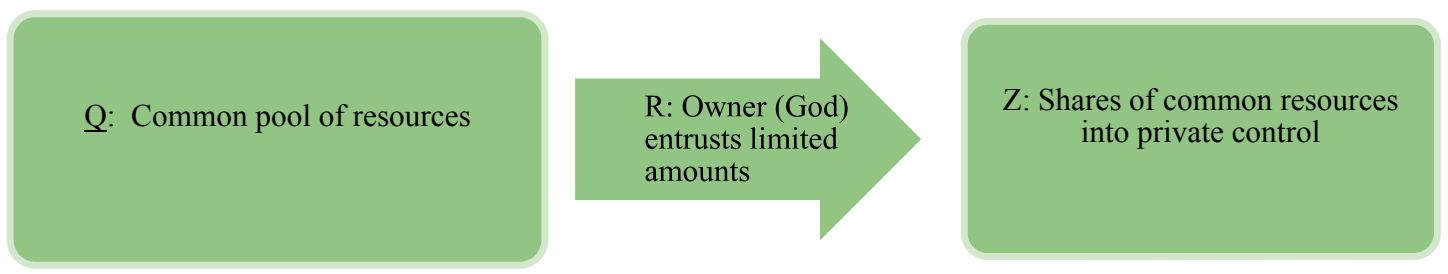

Figure 10. Income (RZQ): Owner (God) entrusts (R) shares (Z) of common resources (Q) into private control.

Firstly, the linguistic paradigm recognizes some macroeconomic precepts. Most importantly, humans cannot take resources or any income with them after death. This is shown as the sound $\mathrm{R}$ which has been deduced to be placed in the "life + economic" row and in the column of the necessary. The flow from the $\underline{Q}$ to the $\mathrm{Z}$ is the $\mathrm{R}$ to show that the relationship between the common pool and the private pool has been converted from spiritual ownership (where no one owns anything) down to economic ownership, where living persons hold ownership. The sound $\mathrm{R}$ in the root RZQ suggests moving limited amounts from the common pool of resources to the private earthly pool. Income is explained through the fact that no resources are owned by anyone, but become privately owned for a certain time. 
Secondly, the linguistic template displays constraints such as the income and budget precepts. An individual's view of possessions (spending) is done by first acquiring from the common pool (natural resources), buying a product after it has had value added, owning it through economic and life circumstances, and finally contributing it back to the earthly possessions through change of ownership or deposit in a waste site. Because $Q$ (pool of common resources) is in the spiritual row, it suggests that acquiring and spending money or expending resources requires accountability, respect, and a sense of duty for relationships. The respect for resources is crucial for conservation. In other words, this suggests that when individuals acquire and expend resources without a spiritual understanding with respect to the constraints, an undue compromise may have an impact on the system for utility maximization and happiness. Moreover, an externality of damage will occur in the common pool of resources, causing widespread minimalization of utility and happiness.

It can be noticed that the linguistic process template agrees with resource economics theory of conservation. Resources have a circular flow: acquiring resources from the common pool, distributing to private ownership, and finally, expending resources back to the common pool.

\section{Process Templates for Equilibrium and Breakdown}

Table 11, Figure 11, and Figure 12 demonstrate equilibrium versus breakdown. The root word for harmonious equilibrium ( $\underline{\mathrm{HQQ}})$ includes an $\underline{\mathrm{H}}$ in the "spiritual + life + economic" row suggesting a holistic integrated process. $\underline{\mathrm{H}}$ is in the first column, suggesting that this process is convergent.

$\underline{Q}$ is in the spiritual row and in the equilibrium column. The root includes two $Q$ 's, suggesting a series of equilibriums. Thus $\underline{\mathrm{HQQ}}$ suggests a convergent time series of (suboptimal) integrated spiritual equilibriums.

The $\underline{H}$ is in the row that includes all aspects of human functioning, as well as the emergent theme that results from the combination of all three: the holistic and systematic approach. Because it does not lack any element, the result is that no one element competes with or takes over another element; everything is under consideration when a consumer makes choices.

Table 11

Specific Concepts for the Sounds of the Word Roots for Equilibrium and Breakdown (in Italics in Row and Column Headings)

\begin{tabular}{|l|l|l|l|l|}
\hline & $\begin{array}{l}\text { closed-self: } \\
\text { convergent, } \\
\text { setback }\end{array}$ & $\begin{array}{l}\text { closed-others: } \\
\text { balance, harmony, } \\
\text { equilibrium }\end{array}$ & $\begin{array}{l}\text { open-self: } \\
\text { imbalance, } \\
\text { flaw, lack }\end{array}$ & open-others \\
\hline containment:spiritual & & $\mathrm{Q}$ & & \\
\hline containment + manifestation & & & & \\
\hline manifestation: life & & $\mathrm{D}$ & $\mathrm{F}$ & \\
\hline spiritual + life + economic: integrated, holistic & $\underline{\mathrm{H}}$ & & & \\
\hline spiritual + economic: series, pattern, trend & $\mathrm{S}$ & & & \\
\hline
\end{tabular}

Q: State of relative spiritual equilibrium

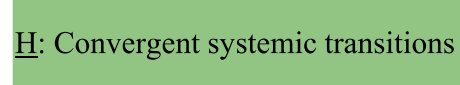

Q: State of relative spiritual equilibrium

Figure 11. Harmonious Equilibrium $(\underline{\mathrm{HQQ}})$ : Convergent series of systemic transitions $(\underline{\mathrm{H}})$ between states of relative spiritual equilibrium ( $\underline{Q}$ to $\underline{Q})$. 
D: State of relative balanced life
S: Down-spiraling series of setbacks
F: State of imbalanced life

Figure 12. Breakdown/Depression/Suicide (FSD): Down-spiraling series of setbacks (S) from states of balanced life (D) to states of imbalanced/flawed/lacking life (F).

The $\mathrm{S}$ in breakdown (FSD) is in the "spiritual + economic" row (containment + assignment), suggesting a series. $\mathrm{S}$ is also in the first column (closed self), suggesting setbacks. Thus, $\mathrm{S}$ is a series of setbacks. $\mathrm{S}$ is the function sound in the template $(\mathrm{S}: \mathrm{F} \leftarrow \mathrm{D})$ : A series of setbacks is converting D back to $\mathrm{F}$. D is in the row of life and the column of balance (closed group), suggesting balanced life, or a life in equilibrium. $\mathrm{F}$ is in the row of life and the column of imbalance (open self: flaw or lack), suggesting imbalanced life.

A breakdown is thus a series of setbacks that gradually increases imbalance in life.

$\mathrm{S}$ being in the "spiritual + economic" row also points to the emergent concept of spiritual management, suggesting that breakdown may be related to spiritual mismanagement.

It can be noticed that $\mathrm{S}$ does not contain an element of life, but it controls life processes $\mathrm{F}$ and $\mathrm{D}$. In other words, this action denies or subverts manifestation of work and relationships. Celebrities display choices of economic freedom through extravagant fashion and consumption, but may or may not regard using spiritual intentions. As a consequence, consumers may become materialistic in their purchases.

The $\mathrm{S}$ being in the first column (closed self) also suggests self-infliction.

\section{Process Templates for Choice of Norm-setter}

Table 12, Figure 13, and Figure 14 demonstrate the effect of the choice of norm-setter. $\underline{\mathrm{O}}$ in the word root OBD (worship: exclusive bond with norm-setter) is in the spiritual row and the "source" column (closed self), suggesting a source of everything spiritual, including norms, energy, resources, truth, intelligence, wisdom, etc. $\mathrm{B}$ is in the "life + economic" row (manifestation + assignment) suggesting a bond, and in the closed-group column, suggesting totality or exclusiveness. $\mathrm{D}$ is in the life row and the same column as B. $\underline{O} B D$ thus give a template that represents a total bond (B) between a powerful spiritual source of everything ( $\underline{\mathrm{O}}$ ) and one's total life (D). This source is genuine in the sense that, as the divine source, it is very likely to deliver all that is expected from it.

Table 12

Specific Concepts for the Sounds of the Word Root for the Choice of Norm-setter (in Italics in Row and Column Headings)

\begin{tabular}{|l|l|l|l|l|}
\hline & $\begin{array}{l}\text { closed-self: } \\
\text { source }\end{array}$ & closed-others: total & open-self & $\begin{array}{l}\text { open-others: } \\
\text { absent }\end{array}$ \\
\hline $\begin{array}{l}\text { containment/spiritual: power, norms, energy, } \\
\text { resources, truth, intelligence, wisdom }\end{array}$ & O & & & \\
\hline $\begin{array}{l}\text { spiritual + life: } \text { norm-setter other than God, } \\
\text { illusory source }\end{array}$ & & & & X \\
\hline manifestation: life & & $\mathrm{D}$ & & \\
\hline spiritual + life + economic & & & & \\
\hline spiritual + economic & & & & \\
\hline life + economic: bond & & $\mathrm{B}$ & & \\
\hline
\end{tabular}


O: Power which is the source of everything spiritual: norms, resources, energy, truth, intelligence, wisdom, ...

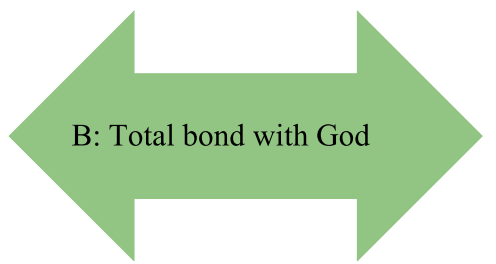

B: Total bond with God

D: One's total life

Figure 13. Exclusive bond with norm-setter God (ㅁBD): Total bond (B) between one's total life (D) and the divine source of everything spiritual, God (ㅁ).
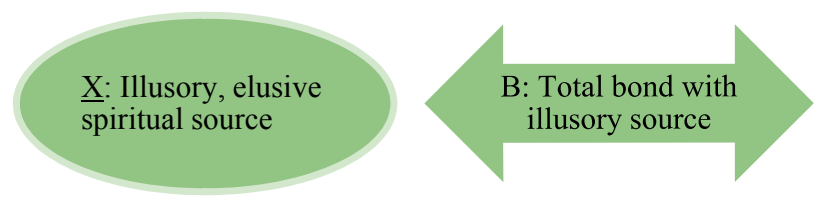

D: One's total life

Figure 14. Bond with another norm-setter in addition to God (XBBD): Because of exclusivity, the existing bond with God is cut, and a total bond (B) is established between one's total life (D) and an illusory spiritual source ( $\underline{X})$

If someone decides to "add" another "total source of everything" to the divine source $\underline{\mathrm{O}}$, then the exclusiveness of this bond will cause an unexpected dramatic effect: The bond with $\underline{\mathrm{O}}$ is then completely disconnected and $\underline{\mathrm{O}}$ is replaced with a source $\underline{X}$ that is a materialistically "heavenly" idol. It possesses all the outward appearances of a norm-setter. It possesses money and fame. It's not known whether this norm-setter has spirituality. The consumer is looking for a way to vicariously live through the celebrity, or they become envious and may develop a psychological disorder.

When a consumer makes choices in this realm, they assess their limitations with respect to income and resources. They are able to make purchases that are not detrimental to them or others. They do so without comparing themselves to others. There is no group-think in this paradigm.

When consumers observe successful people using this template, they would focus on the ways the successful people utilized their spiritual resources. They distinguish between a spiritual role model and a spiritual source. They become objective buyers and are not subjected to brand name images.

\section{Conclusions}

Different systems for organizing the thinking of consumers were compared. Depending on the choice of norms and norm-setters, consumers may use different decision-making strategies in the search for happiness. The linguistic paradigm which was introduced in this study is based on the nature of human language as a system for organizing human thinking. This paradigm is revealed through the original language of divine norms in the form of word-root-based process templates which constitute models of thinking and behavior. The linguistic paradigm supports the observation that consumer choices are not only related to income, expenditure, and utility, but spirituality as well. Behavioral economics suggests that people behave through the subconscious in order to maximize utility. This study sets up a logical framework to include spirituality in econometrics. This framework offers models for creating statistical surveys and hypotheses, and tools for assessing and explaining different patterns of consumer behavior. Similarly, the linguistic paradigm offers models for the broader field of economics and for other fields of the study of human processes and real world phenomena. 


\section{References}

Adi, T. (1989). Method and apparatus to identify the relation of meaning between words in text expressions, U.S. Patent 4,848,898. Retrieved from https://patentimages.storage.googleapis.com/pdfs/US4849898.pdf

Adi, T. (2007). A theory of semantics based on old Arabic. In R. Gudwin, \& J. Queiroz (Eds.), Semiotics and intelligent systems development (pp. 176-209). Hershey: IGI Global.

Adi, T. (2009). A theory of emotions based on natural language semantics. In J. Vallverdú, \& D. Casacuberta (Eds.), Handbook of research on synthetic emotions and sociable robotics, new applications in affective computing and artificial intelligence. Hershey IGI Global.

Adi, T., \& Ewell, O. K. (1987). Letter semantics in Arabic morphology. Proceedings from the Morphology Workshop of the 1987 Linguistic Institute Conference, Stanford, CA. Retrieved July 2008, from http://www.readware.com/papers/ltr_sem.doc

Adi, T., Ewell, O. K., \& Adi, P. (1999). Readware text analysis and retrieval in TREC 7. In E. Voorhees, \& D. Harman (Eds.), NIST special publication 500-242: The seventh Text Retrieval Conference (TREC-7), 461-464. Department of Commerce, National Institute of Standards and Technology. Retrieved July 2008 from http://readware.com/Papers.htm

Adi, T., Ewell, O. K., \& Adi, P. (2000). High selectivity and accuracy with readware's automated system of knowledge organization. In E. Voorhees, \& D. Harman (Eds.), NIST special publication 500-246: The eighth Text REtrieval Conference (TREC-8), 493-499. Retrieved July 2008 from http://readware.com/Papers.html

Adi, T., Ewell, O. K., Adi, P., \& Vogel, T. (2009). A new theory of cognition and software implementations in information technology. Journal of Information Technology Research (JITR), 2(2), 65-89.

Adi, T., Ewell, O. K., Vogel, T., Payton, K., \& Hippchen, J. L. (2014). Adaptive interoperable models of all things based on human language. Encyclopedia of Information Science and Technology, Third Edition. Hershey: IGI Global.

Adi, T., Ewell, O. K., Vogel, T., Payton, K., \& Hippchen, J. L. (2013). Muhkam algorithmic models of real world processes for intelligent technologies. International Journal of Robotics Applications and Technologies, 1(2), 56-82.

Akerlof, G. A., \& Kranton, R. E. (2000). Economics and identity. The Quarterly Journal of Economics, 115(3), 715-753.

Akerlof, G. A., \& Kranton, R. E. (2010). Identity economics. Princeton: Princeton University Press.

Al-Qur'an (1992). Medina: Mujamma Publishers.

Al-Shatibi, A. I. (1996). Al-muwafaqat fi usul al-sharia. Beirut: Dar Al-Marifa.

Huettel, S. A., \& Kranton, R. E. (2012). Identity economics and the brain: Uncovering the mechanisms of social conflict. Philosophical Transactions of the Royal Society B, 367, 680-691.

Johnston-Greene, C. (2009). AARP shows largest growth in readership. Folio Magazine. Retrieved September 9, 2012 from http://www.foliomag.com/2009/aarp-shows-largest-readership-growth-people-largest-audience

Karch, D. L., Logan, J., McDaniel, D., Parks, S., \& Patel, N. (2012). Surveillance for violent deaths-National violent death reporting system, 16 States, 2009 (MMWR Surveillance Summary 2012; 61:1-43). Retrieved from http://www.cdc.gov/mmwr/preview/mmwrhtml/ss6106a1.htm?s_cid=ss6106a1_e\#tab6

Saussure, F. (1916). Cours de linguistique générale. Paris: Payot.

Time Warner Cable Inc. (2013). Company profile (Reference Code: 89401F85-320F-4395-B193-FFA41FC19F92, Publication Date: 17 Dec 2013). Retrieved from www.marketline.com

TREC Conference. (2000). Overview. Retrieved July 2008 from http://trec.nist.gov/overview.html

Voorhees, E., \& Harman, D. (2000). Overview of the eighth text retrieval conference (TREC-8). Retrieved from http://trec.nist.gov/pubs/trec8/papers/overview_8.pdf 